\title{
Prevalence of Knee Pain in Football Players of Various Age Group
}

\author{
Bhakti Mangesh Naik ${ }^{1}$, Manali Akre², Ajay Kumar ${ }^{3}$ \\ ${ }^{1}$ Graduate, DPO's Nett College of Physiotherapy, Kolshet Road, Opposite Everest World, Thane, India \\ ${ }^{2}$ Assistant Professor, DPO's Nett College of Physiotherapy, Kolshet Road, Opposite Everest World, Thane, \\ India \\ ${ }^{3}$ Principal, DPO's Nett College of Physiotherapy, Kolshet Road, Opposite Everest World, Thane, India
}

Corresponding Author: Bhakti Mangesh Naik

\begin{abstract}
Background: Football is the most commonly played sport at both elite and grassroots level in many countries. Football is a sport that involves intermittent walking, jogging, running, and sprinting. Football players are at high risk for lower extremity injuries because they turn on an axis of rotation, repeatedly jump and land. One of the most common sites of injury is the knee. To identify instruments like pain, function, and activity level fulfilling these criteria, Knee pain were assessed with published reviews of knee instruments IKDC (International Knee Documentation Committee) and self - reported pain questionnaire. This study contains data only applicable to the knee.
\end{abstract}

Aim: To find out the prevalence of knee pain in football players of various age group.

Objectives: To find the prevalence of knee pain in football players using self - reported pain questionnaire and IKDC and also to find out influence of gender in football players of various age group.

Materials and methods: 250 football players were selected as per the inclusion and exclusion criteria and consent was taken.

Knee pain was assessed with the self reported pain questionnaire and IKDC Form. The data were obtained and statistically analysed.

Result: The study results show that knee pain is prevalent in football players of various age group.

Conclusion: The above study concludes knee pain is prevalent in football players, it's more prevalent in male also common in dominant side of knee and age of onset is 10-15 years of age group.

Keywords: Knee pain, IKDC, Pain Questionnaire, Football Players.

\section{INTRODUCTION}

Football in India has existed in many forms since the game first arrived in the country during the 19th century with the first nationwide club competition, the Durand Cup, being founded in 1888 . $^{(1)(2)}$

Football is the most commonly played sport at both elite and grassroots level in many countries. A survey carried out by the German Olympic Sports Confederation found that football is by far the most popular sport among male children ( 7 to 14 years) and adolescents (15 to 18 years). For girls in these age groups, football is second only to gymnastics. Overall, it can be assumed that around 1.65 million boys and 300000 girls in Germany currently play football on an organized basis. ${ }^{(5)}$

Football is a sport that involves intermittent walking, jogging, running and sprinting. Football players are at high risk for lower extremity injuries because they turn on an axis of rotation, turn while decelerating, and repeatedly jump and land. One of the most common sites of injury is the knee. ${ }^{(6)}$ 
The knee is particularly susceptible to injury, as it is the centre of the lever of the leg, and sustains greater forces transmitted from the ground through the ankle and foot, as well as from the trunk down through the hip.

Professional footballers who have never suffered a major injury to the knee joint have a significantly elevated risk of knee osteoarthritis. Alongside the increased prevalence of knee joint problems in general and osteoarthritis in particular, exprofessional football players have been found to have a high (55 to 63\%) incidence of genu varum. For adults there is strong evidence that genu varum accelerates the progress of knee osteoarthritis. ${ }^{(5)}$

The knee is the largest joint and one of the most important joints in the body. It plays an essential role in movement related to carrying the body weight in horizontal (running and walking) and vertical (jumping) directions.

Knee functions are important for the comprehensive assessment of rheumatology conditions in both clinical and research contexts. To merit inclusion in this review, measures of knee function were required to be players reported and assess aspects considered important by players with knee problems such as pain, injury. Dimensions deemed to be important to patients included pain, function, and activity level. To identify instruments fulfilling these criteria, we were utilized published reviews of knee instruments, IKDC (International Knee Documentation Committee Subjective Knee Evaluation.) ${ }^{(9)}$

We were included the following reported self - reported pain questionnaire outcomes although the IKDC, this study were contains data only applicable to the knee. Measures assessing activity level are listed separately.

The IKDC was formed in 1987 to develop a standardized international documentation system for knee conditions. It was subsequently published in 1993 and revised in 1994. It was developed as a revision of the Standard Knee Evaluation
Form in 1997. It has undergone subsequent minor revisions since its publication in 2001. The items now have the allocated scores next to each possible response. The minimum score for each item has also been changed so that it is now 0 , not 1 . The scoring of the numerical rating scales for items 2 and 3 has been reversed so that 0 represents the highest level of symptoms and 10 represents the lowest level of symptoms. ${ }^{(9)}$

The IKDC Form is freely available. In this contains data only applicable to the knee. It uses simple language that is suitable for patients. 10 minutes to complete the scale. And Approximately 5 minutes to score. Training is not necessary. Manual scoring can be performed easily using the scoring instructions supplied with the questionnaire. $^{(10)}$

\section{MATERIALS AND METHODS}

This study is Cross sectional study. This study involved 250 football players chosen by convenient sampling from Clubs in metropolitan city. Subject who were willing to participate in the study and playing for 2-3 hours daily for 1- 2 years were included in the study and subjects who are medically not fit and with recent surgeries were excluded from the study. Consent was taken. The materials required for the study were pen and paper. Knee pain was assessed with the self reported pain questionnaire and IKDC subjective Knee Evaluation Form. Data were obtained and statistically analysed.

\section{RESULTS AND ANALYSIS}

Table 1: Knee Pain Analysis

\begin{tabular}{|l|l|} 
Table 1: Knee Pain Analysis \\
\begin{tabular}{|l|l|l|}
\hline Pain & No. of Players \\
\hline Yes & 141 & $56.4 \%$ \\
\hline No & 109 & $43.2 \%$ \\
\hline Total & 250 & \\
\hline
\end{tabular}
\end{tabular}

Table 1 represents knee pain analysis on selected sample size, $56.4 \%$ of population were having knee pain. 


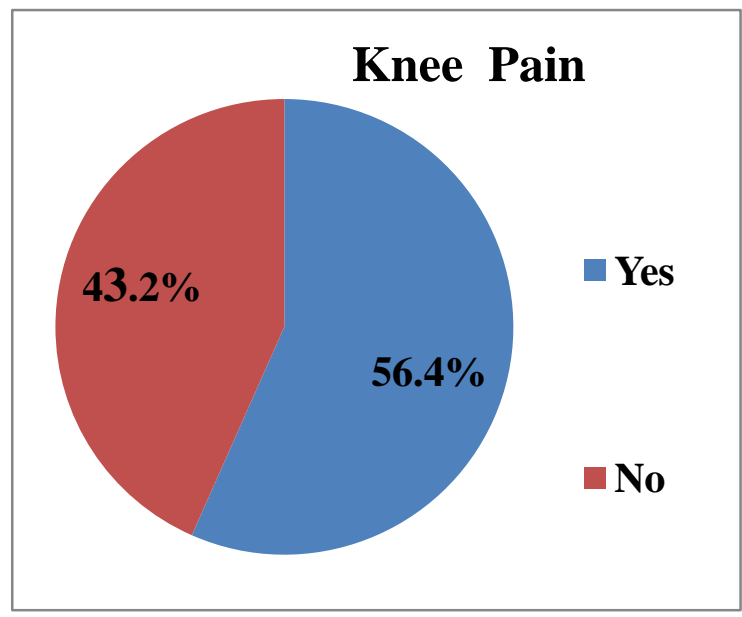

Graph 1: Pain Analysis

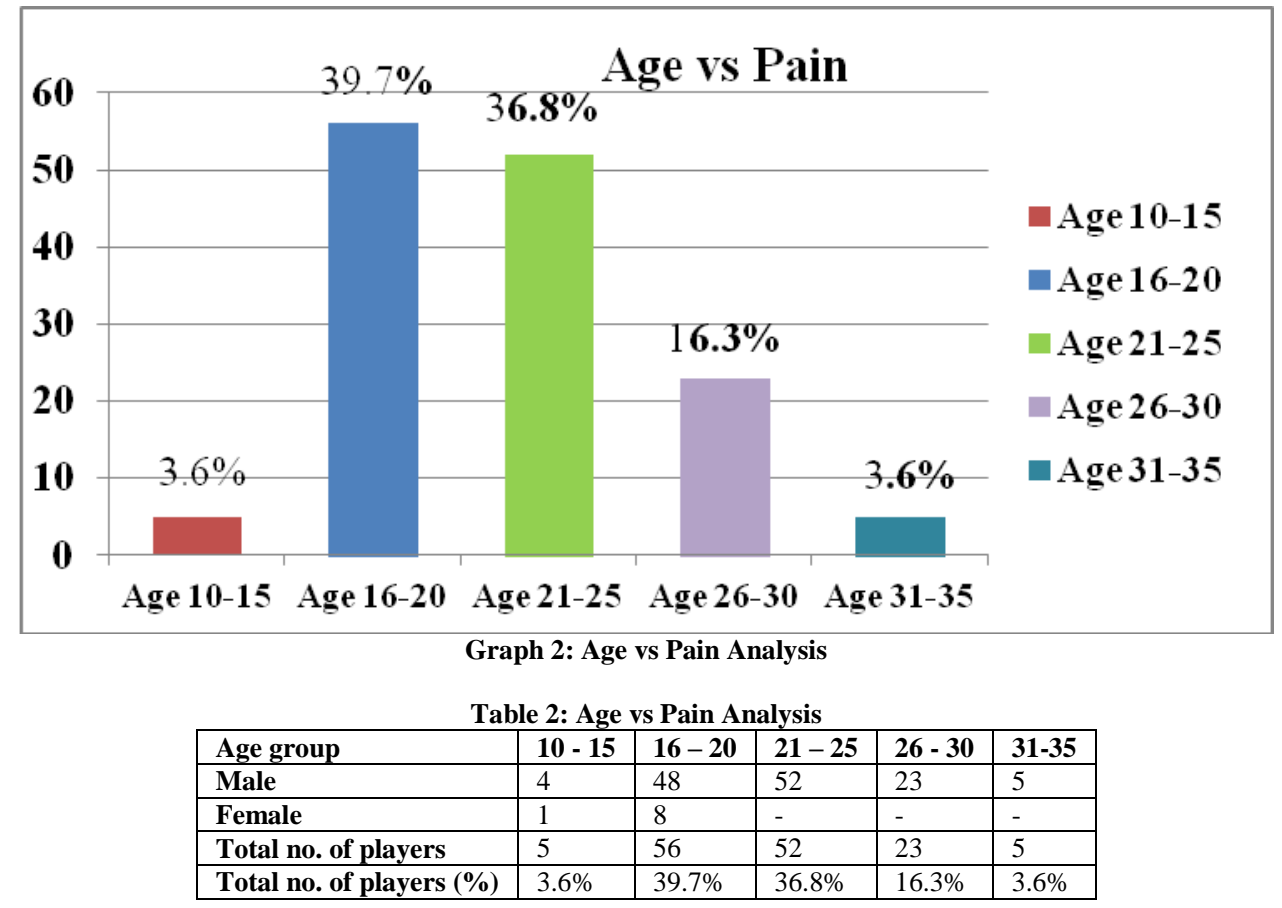

Table 2 represents distribution of the commonest age having knee pain. Age knee pain on selected sample size based on their age. The above showed age groups are of onset of pain among players was 10-15 year old.

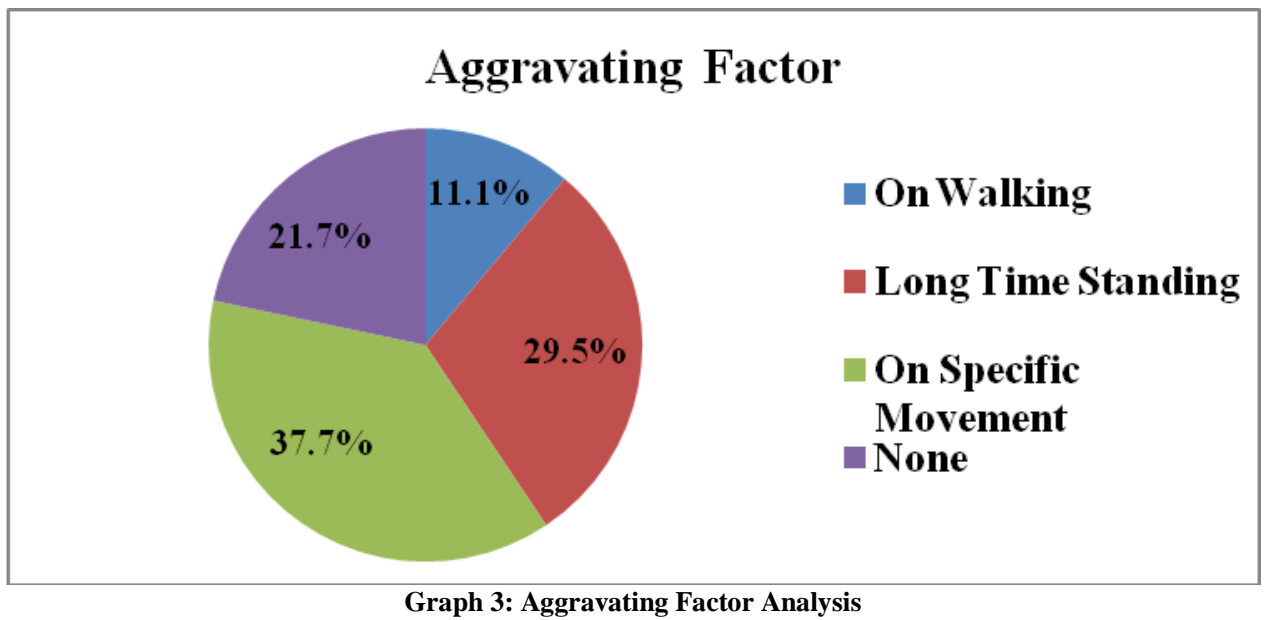


Table 3: Aggravating Factor Analysis

\begin{tabular}{|l|l|l|l|l|}
\hline \multicolumn{5}{|l|}{ Aggravating Factor } \\
\hline & On Walking & Long Time Standing & On Specific Movement & None \\
\hline No. of Players & 23 & 61 & 78 & 45 \\
\hline No. of Players (\%) & $11.1 \%$ & $29.5 \%$ & $37.7 \%$ & $21.7 \%$ \\
\hline
\end{tabular}

Table 3 shows that the players who were suffering from pain, there aggravating factors were prolong standing and pain with specific movement.

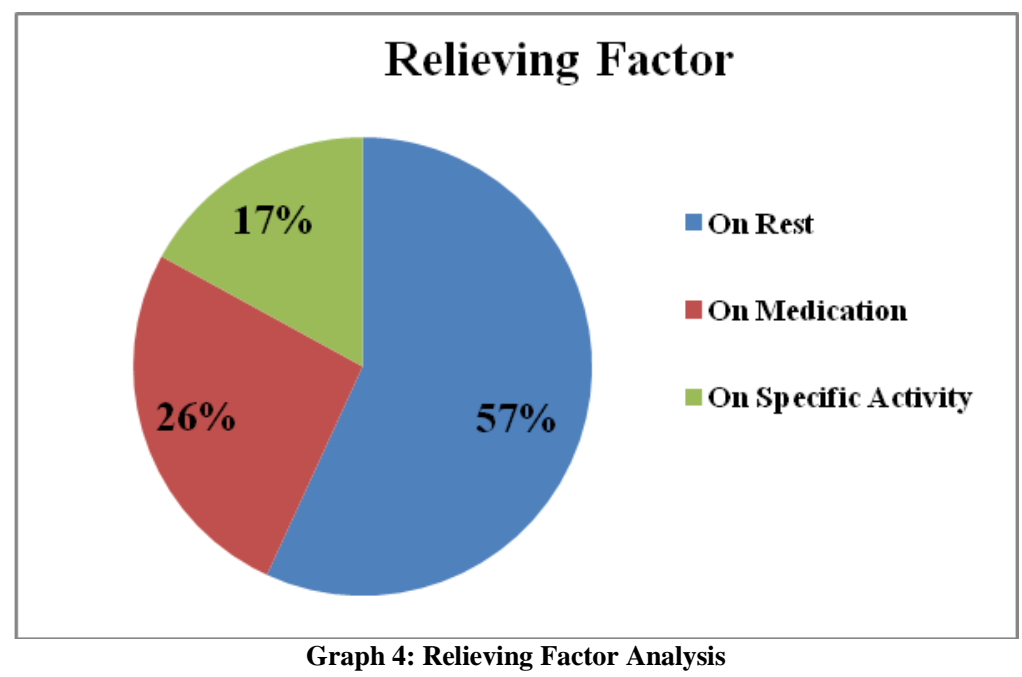

Table 4: Relieving Factor Analysis

\begin{tabular}{|c|c|c|c|}
\hline \multicolumn{4}{|l|}{ Relieving Factor } \\
\hline & $\begin{array}{l}\text { On } \\
\text { Rest }\end{array}$ & $\begin{array}{l}\text { On } \\
\text { Medication }\end{array}$ & $\begin{array}{l}\text { On Specific } \\
\text { Activity }\end{array}$ \\
\hline No. of Players & 100 & 46 & 30 \\
\hline $\begin{array}{l}\text { No. of Players } \\
(\%)\end{array}$ & $57 \%$ & $26 \%$ & $17 \%$ \\
\hline
\end{tabular}

Table 4 shows that $57 \%$ population got relief from pain after taking rest, 26\% after taking medication and $17 \%$ on specific activity.

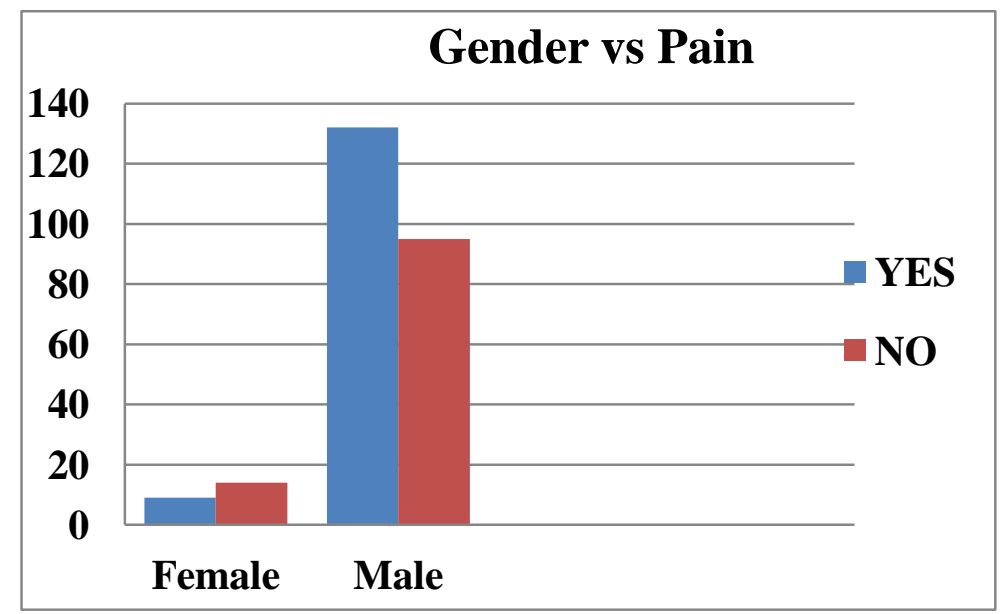

Graph 5: Gender vs Pain Analysis

Table 5: Gender vs Pain Analysis

\begin{tabular}{|l|l|l|}
\hline \multirow{2}{*}{ Pain } & Gender \\
\cline { 2 - 3 } & Male & Female \\
\hline Yes & 132 & 9 \\
\hline No & 95 & 14 \\
\hline Grand Total & 227 & 23 \\
\hline Yes (\%) & $58.2 \%$ & $39.2 \%$ \\
\hline No (\%) & $41.8 \%$ & $60.8 \%$ \\
\hline
\end{tabular}

Table 5 represents Pain distribution among Gender, since $58.2 \%$ male players were having knee pain which is more than female football players (39.2\%). The knee pain was more prevalent in male than female football players. 


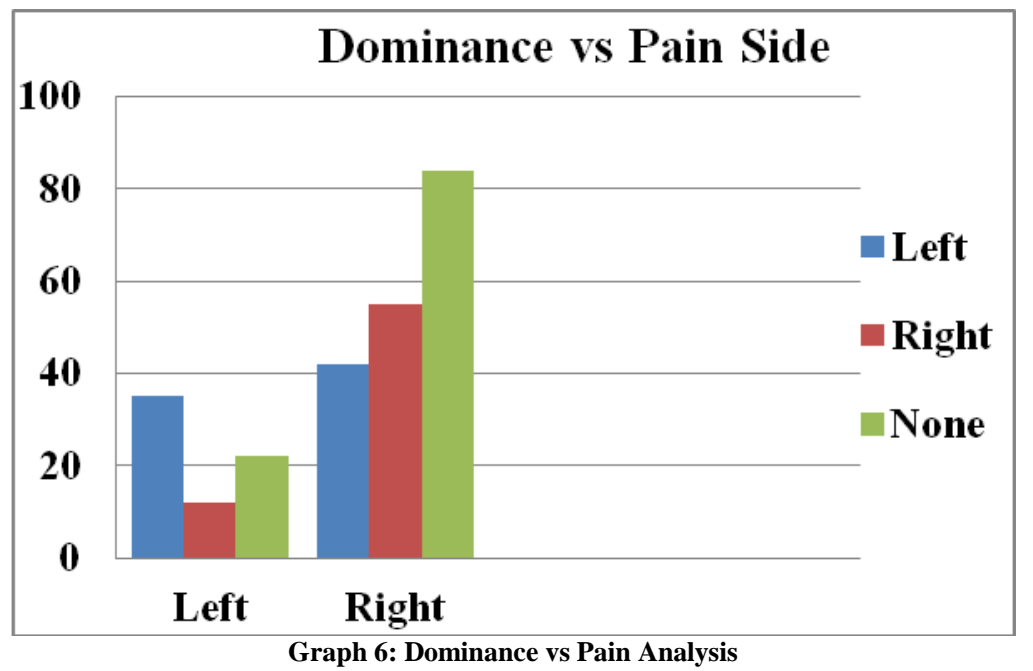

Table 6: Dominance vs Pain Analysis

\begin{tabular}{|l|l|l|l|}
\hline \multirow{2}{*}{ Dominance } & Pain Side & \multicolumn{2}{|l|}{} \\
\cline { 2 - 4 } & Left & Right & None \\
\hline Left & 35 & 12 & 22 \\
\hline Right & 42 & 55 & 84 \\
\hline Left & $51.5 \%$ & $12.1 \%$ & $36.4 \%$ \\
\hline Right & $22.8 \%$ & $31.5 \%$ & $45.6 \%$ \\
\hline
\end{tabular}

Table 6 represents Dominance vs Pain relation. $51.5 \%$ left dominance football players were having knee pain on left side and $31.5 \%$ right dominance football players were having knee pain on right side. This showed that the knee pain is most prevalent on the basis of dominance.

\section{DISCUSSION}

This study was an attempt to identify the prevalence of knee pain in football players by considering whole population and enabling to understand cause and age of onset of knee pain, which is epidemiological importance.

Football is a sport that involves intermittent walking, jogging, running, and sprinting. Football players are at high risk for lower extremity injuries because they turn on an axis of rotation, turn while decelerating, and repeatedly jump and land. One of the most common sites of injury is the knee. ${ }^{(6)}$

The knee is particularly susceptible to injury, as it is the centre of the lever of the leg, and sustains greater forces transmitted from the ground through the ankle and foot, as well as from the trunk down through the hip.
Knee functions are important for the comprehensive assessment of rheumatology conditions in both clinical and research contexts. To merit inclusion in this review, measures of knee function were required to be players reported and assess aspects considered important by players with knee problems such as pain, injury. Dimensions deemed to be important to patients included pain, function, and activity level. To identify instruments fulfilling these criteria, we utilized published reviews of knee instruments, IKDC. ${ }^{(9)}$

We included the self - reported pain questionnaire outcomes although the IKDC Subjective Knee Evaluation Form, this study were contains data only applicable to the knee. Measures assessing activity level are listed separately.

The present study showed that there was $56.4 \%$ population is having knee pain between all age groups. $54.8 \%$ of male players suffering from knee pain between all age group. As the distribution of pain in gender showed that since $58.2 \%$ male football players are having knee pain which $\%$ were more than female football players (39.2\%), male football players are more susceptible to knee pain. Football players those suffering from knee pain most of them pain aggravating factors were doing specific movement and long time standing. And also $57 \%$ population saying that they gets relief from pain while taking rest very few were prefers medication and specific activity. In 
dominance vs pain relation is representing that $51.5 \%$ left dominance football players were having knee pain on left side and $31.5 \%$ right dominance football players were having knee pain on right side. The study showed that the knee pain is most prominent on side of dominance.

Result of this study show that there is prevalence of knee pain in football players of various age group, this could be due to, a sudden injury e.g. a sprain / strain / contusion. ${ }^{(12)}$ Knee injury is the main attributable risk factor. Even after adjustment for recognized risk factors, knee osteoarthritis appears to be an occupational hazard of professional football. ${ }^{(11)}$

\section{CONCLUSION}

Thus study concluded that the knee pain is prevalent in football players, it's more prevalent in male also common in dominant side of knee and age of onset is $10-15$ years of age group.

\section{ACKNOWLEDGEMENT}

I would like to show my greatest appreciation to respected sir Dr. Ajay Kumar. I am grateful of Dr. Manali Akre who helped me choosing my project topic and supported thoroughly on the way. Her willingness to motivate me contributed tremendously to my project. I also take this opportunity to thank my family members and friends for their help and support.

\section{Conflict of Interest: None}

\section{Source of Funding: None}

\section{Ethical Approval: Approved}

\section{REFERENCES}

1. Sarkar, Monica (6 May 2013) "While Indian football sleeps, its young hopefuls dream of playing abroad" CNN. Retrieved 13 August 2017.

2. Mergulhao, Marcus "Asia's Oldest Football Event Gets New Home". Times of India. Retrieved; 13 August 2017(1).

3. Milles, James; Dimeo, Paul (2001). Soccer in South Asia: Empire, Nation, Diaspora
4. "Soutik Biswas's India: Why is India not at the World Cup?" BBC. 2010-06-18. Retrieved 2014-02-15.

5. Thaller PH, Fürmetz J, Chen F, Degen N, Manz KM, Wolf F. Bowlegs and Intensive Football Training in Children and Adolescents: A Systematic Review and Meta-Analysis. Deutsches Ärzteblatt International. 2018 Jun; 115(24):401.

6. Lee SM, Lee JH. Effect of balance taping using kinesiology tape for a hamstring muscle injury and traumatic knee pain in an amateur university football player: A case report. Medicine. 2018 Jun; 97(23).

7. Waldén $M$, Atroshi I, Magnusson $\mathrm{H}$, Wagner P, Hägglund M. Prevention of acute knee injuries in adolescent female football players: cluster randomised controlled trial. Bmj. 2012 May 3; 344:e3042.

8. Salzmann GM, Preiss S, Zenobi-Wong M, Harder LP, Maier D, Dvorák J. Osteoarthritis in football: with a special focus on knee joint degeneration. Cartilage. 2017 Apr; 8(2):162-72.

9. Collins NJ, Misra D, Felson DT, Crossley KM, Roos EM. Measures of knee function: International Knee Documentation Committee (IKDC) Subjective Knee Evaluation Form, Knee Injury and Osteoarthritis Outcome Score (KOOS), Knee Injury and Osteoarthritis Outcome Score Physical Function Short Form (KOOS-PS), Knee Outcome Survey Activities of Daily Living Scale (KOSADL), Lysholm Knee Scoring Scale, Oxford Knee Score (OKS), Western Ontario and McMaster Universities Osteoarthritis Index (WOMAC), Activity Rating Scale (ARS), and Tegner Activity Score (TAS). Arthritis care \& research. 2011 Nov; 63(S11):S208-28.

10. Krajnc Z, Vogrin M, Rečnik G, Crnjac A, Drobnič M, Antolič V. Increased risk of knee injuries and osteoarthritis in the nondominant leg of former professional football players. Wiener Klinische Wochenschrift. 2010 May 1;122(2):40-3.

11. Fernandes GS, Parekh SM, Moses J, Fuller C, Scammell B, Batt ME, Zhang W, Doherty M. Prevalence of knee pain, radiographic osteoarthritis and arthroplasty in retired professional footballers compared with men in the general population: a crosssectional study. Br J Sports Med. 2018 May 1;52(10):678-83. 
12. Kumar A, Pimpale S, Bhoite A. Prevalence of Knee Pain in Karate Students of Age Group 15 to 25 Years. Indian Journal of Physiotherapy \& Occupational Therapy. 2017 Oct 1;11(4).

13. Guddal MH, Stensland SØ, Småstuen MC, Johnsen MB, Zwart JA, Storheim K. Physical activity level and sport participation in relation to musculoskeletal pain in a population-based study of adolescents: the young-HUNT study. Orthopaedic Journal of Sports Medicine. 2017 Jan 27;5(1):2325967116685543.

14. McAlindon TE, Cooper C, Kirwan JR, Dieppe PA. Knee pain and disability in the community. Rheumatology. 1992 Mar 1;31(3):189-92.
15. Higgins LD, Taylor MK, Park D, Ghodadra $\mathrm{N}$, Marchant M, Pietrobon R, Cook C. Reliability and validity of the International Knee Documentation Committee (IKDC) subjective knee form. Joint Bone Spine. 2007 Dec 1;74(6):594-9.

16. Waldén M, Hägglund M, Ekstrand J. High risk of new knee injury in elite footballers with previous anterior cruciate ligament injury. British journal of sports medicine. 2006 Feb 1;40(2):158-62.

How to cite this article: Naik BM, Akre M, Kumar A. Prevalence of knee pain in football players of various age group. Int $\mathrm{J}$ Health Sci Res. 2021; 11(4): 299-305. DOI: https://doi.org/10.52403/ijhsr.20210435 